\title{
Repeated Impact of Simulated Hail Ice on Glass Fibre Composite Materials
}

\author{
Hamish Macdonald ${ }^{\mathrm{a}, *}$, David Nash ${ }^{\mathrm{b}}$, Margaret Stack ${ }^{\mathrm{b}}$ \\ ${ }^{a}$ Wind Energy Systems CDT, University of Strathclyde, Glasgow, UK \\ ${ }^{b}$ Mechanical and Aerospace Engineering, University of Strathclyde, Glasgow, UK
}

\begin{abstract}
Wind turbine blade damage, particularly leading edge erosion, is a significant problem faced by the renewable energy industry. Wind turbines are subject to a wide range of environmental factors during a 20+ year lifespan, with hailstones often touted as a key contributor to the deterioration of the blade profile. An experimental campaign was carried out to investigate the effects of repeated impact of smaller diameter simulated hail ice (SHI) on composite materials, to correspond to those most prevalent at wind farm locations. Hailstones of four different diameters $(5 \mathrm{~mm}, 10 \mathrm{~mm}$, $15 \mathrm{~mm}$ and $20 \mathrm{~mm}$ ) were fired at velocities in the range of $50 \mathrm{~m} \mathrm{~s}^{-1}$ to $95 \mathrm{~m} \mathrm{~s}^{-1}$. Samples used for experimentation were manufactured from triaxial stitched glass fibre $\left[0^{\circ} /-45^{\circ} /+45^{\circ}\right]$ and epoxy resin. Damage was evaluated in terms of sample mass loss and microscopy of the composite surface. For all examples, mass loss was negligible and optical microscopy showed little evidence of surface damage. Surface degradation was discernible under scanning electron microscopy for the larger diameter SHI $(\geq 15 \mathrm{~mm}$ ), with projectile velocity a notable factor in the extent of the damage. Even for large numbers of impacts, there was little noteworthy damage caused by smaller, more prevalent SHI $(\leq 10 \mathrm{~mm})$. This suggests that hail is not a direct cause of wind turbine blade erosion.
\end{abstract}

Keywords: hail, damage, wind turbine, glass fibre

\section{Introduction}

\subsection{Wind Turbine Blade Damage}

Damage is manifested in many different guises and locations along the length of a wind turbine blade [1]. The severity of damage can range from cosmetic, whereby the turbine can continue to operate, to critical where immediate action is required and the turbine has to be shut-down, resulting in lost production. Any corrective maintenance activities associated with blade damage is a major consideration, especially with the increasing trend of larger turbines and wind farm installations located offshore. There are high cost and health \& safety implications for even with minor repairs as technicians have to transported to the asset and traditionally carry out the work using rope access methods. Blade replacement offshore would be a considerable task, with costly "jack-up" vessels utilised for such operations.

Depending on the geographic location of installation, wind turbines can be subject to a range of airborne par-

\footnotetext{
${ }^{*}$ Corresponding author

Email address: hamish.m.macdonald@strath.ac.uk (Hamish Macdonald )
}

Preprint submitted to Elsevier ticles throughout a lifetime of operation. These particles, along with other environmental factors, are linked to the degradation of the material characteristics of wind turbine blades. Included in these considerations are hail and the various forms and sizes they can represent. Typically, the resultant damage from impact on composites is apparent in the form of transverse cracks (matrix cracking), separation of plies from delamination. Fibre cracking is also a possibility, which can reduce the strength of the composite by up to $1 / 3$ [2].

Another notable form of environmental damage is erosion, typically experienced on the leading edge of wind turbine blades. Observations from wind farm sites have described a progressive deterioration of the leading edge and other surfaces of the section that can alter the aerodynamic profile of the blade and result in a reduction in annual energy production (AEP). The removal of the protective surface of the composite can expose the substrate beneath, leading to water ingress and moisture absorption. This could also result in an unbalanced rotor, providing further risk to other connected components located throughout the turbine. 


\subsection{Hail Characteristics}

The general classification of "hail" covers a range of distinctive categories. The major types of ice particles that fall under this banner include graupel, small hail, ice pellets and hailstones. Also considered by the World Meteorological Organisation in the classification of a "hail day" are snow grains and diamond dust [3]. All hail growth stems from nuclei, $0.1-1 \mu \mathrm{m}$ in diameter, such as: cloud condensation, dust or salt. The eventual form and size of hail is dependent on the length of time that it can spend in a convective cloud before descending to the ground. In larger hailstones, the alternation of wet and dry growth modes can lead to a spherically layered, "onion-like" structure.

The understanding of the material properties of hail ice is limited due to complexity and highly variable nature of its formation. As such it is often represented by polycrystalline ice. One of the most notable features of ice under compression, is the behaviour exhibited at different rates of strain. High low and intermediate strain rates give rise to ductile behaviour and high rates result in brittle behaviour. Additional engineering properties of ice are detailed by Schulson [4] and Petrovic [5].

\subsection{Experimental Studies of Hail Impact on Composite Materials}

The effects of hailstone impact on composite materials have been investigated previously, with numerous experimental and computational studies available. Olsson et al. [6] provide a summary of the issue of high velocity hail impact on composite laminates. One of the earliest investigations by Mahinfalah and Skordahl [2] compared the effects of high velocity ice projectiles to aluminium spheres. Extensive studies have also been carried out by Kim and associates [7, 8, 9, 10] to determine the impact response damage from artificial hailstones. The term simulated hail ice (SHI) was coined from attempts to replicate authentic hailstones in the form of monolithic and "flat-wise layered" spheres. Failure modes were also determined from this, with increasing levels of damage visibility and material penetration observed from increasing velocity/energy [7].

The majority of this research, pertains to aerospace structures and the related conditions of such applications. Primarily this involves singular impact of extreme sizes of hail at speeds that are associated with aircraft operation. Even within an EASA report on the threat of hail[11], there is a recommendation to consider the effect of multiple hits by hail smaller than $50 \mathrm{~mm}$ in diameter needs to be considered in aircraft design.

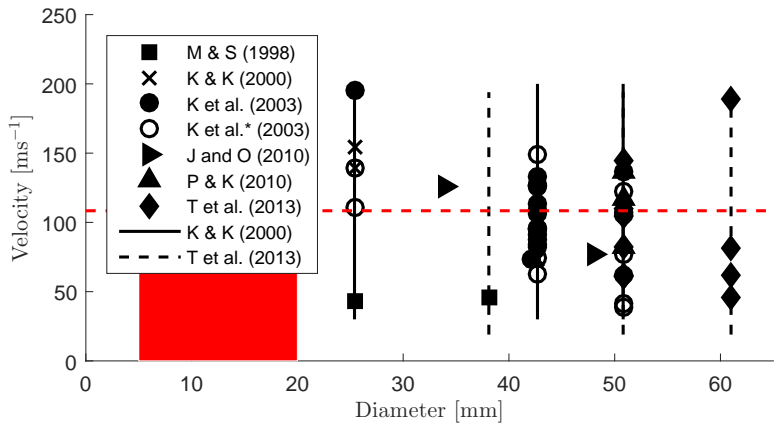

Figure 1: Example SHI impact velocities and diameters (line plots indicate diameter range) [M \& S - Mahinfalah \& Skordal [2], K \& K - Kim \& Kedward [7], K et al. - Kim et al. [8], * - estimated, J \& O - Juntikka and Olsson [14], P \& K - Park \& Kim [15], T et al. Tippmann et al. [10]].

Appleby-Thomas et al. [12] present one of the few examples of repeated impact but again using large ice projectiles greater than $20 \mathrm{~mm}$ in diameter.

\subsection{Hail Considerations for Wind Turbine}

A meteorological study, conducted by Macdonald $e t$ al. [13] generated a likelihood of hail impact conditions in relation to UK wind turbine locations. Over a 65 year period, the prevalence of smaller diameter hail incidents $(\leq 10 \mathrm{~mm})$ was found to be much greater than the rare events of extreme sized hailstones $(\geq 20 \mathrm{~mm})$ that are typically utilised in the aforementioned literature. Therefore there is a significant gap in hail experimental research that involve repeated impact of smaller sizes of hail on composites and the aim of this investigation was to carry out an experiments that are appropriately aligned with these meteorological findings. The influence of impact velocity is also be assessed, which can reduced to a combination of the following velocity components: the hail fall speed; the wind speed; and the wind turbine speed. The rotational speed of the wind turbine is by far the dominating velocity component, with the tip-speeds at the blades of modern machines have exceeded $100 \mathrm{~m} \mathrm{~s}^{-1}$. The dearth of data in the diameter-velocity range that would be applicable to frequent wind turbine hail impact is indicated by the red region in Figure 1

\section{Materials and Methods}

\subsection{Experimental set-up}

Simulated hail ice (SHI) was fired at composite samples using a vertically orientated experimental rig, as described in Figure 2. The speed of the projectile was var- 


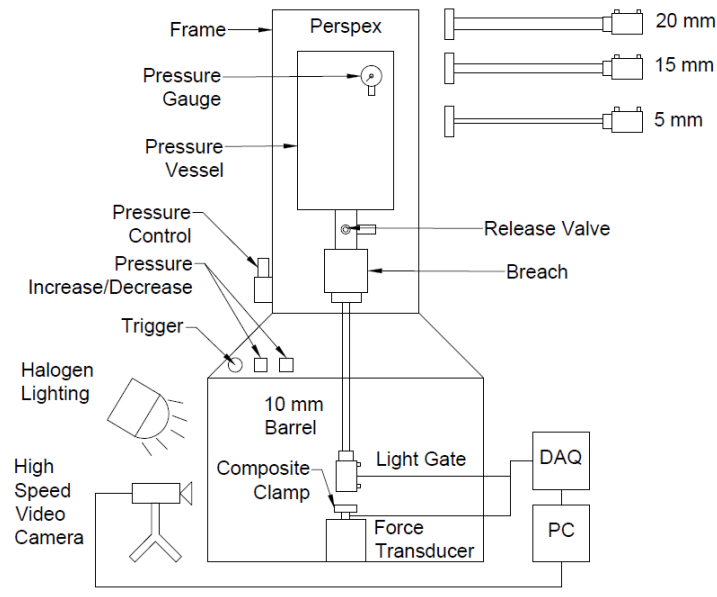

Figure 2: Schematic the experimental rig used for Simulated Hail Ice (SHI) impacts.

ied by altering the level of pressure in the vessel. Separate, detachable barrels and associated plastic sabots were utilised to launch different diameters of hailstones.

Ice projectiles were created using PTFE polymer moulds. Four different sizes of mould in two hemispherical halves allowed for the creation of 5, 10, 15 and $20 \mathrm{~mm}$ diameter SHI, informed from the meteorological study. Each individual sphere in the mould was connected to a small diameter aperture so that the solution could be inserted using a hypodermic needle. This consisted of room-temperature distilled water and a small drop of household black dye, that would assist in the accurate measurement of projectile velocity. Before the filling process was carried out the PTFE was sprayed with mould release, to facilitate the safe removal of the spheres after freezing. The mould halves were aligned using guiding pins, then fixed tightly together using aluminium clamping plates. Once filled, the assembly was placed upright in a chest freezer at a temperature of $-24^{\circ} \mathrm{C}$. Freezing times for each diameter of SHI were estimated using empirical heat transfer relations and then rounded up to the nearest hour, resulting in a minimum of $\sim 1 \mathrm{~h}$ for the smallest and $\sim 3 \mathrm{~h}$ for the largest projectile. The individual monolithic spheres were removed carefully using plastic tweezers and returned to the freezer for storage. The smaller, more delicate $5 \mathrm{~mm}$ and $10 \mathrm{~mm}$ diameters of SHI were kept in individually spaced polypropylene containers so that they would not adhere to each other. The larger sizes were placed in polythene bags.

The selection of composite materials was informed by the more recent tendency of using multi-axial glass fibre reinforced polymer (GFRP) in wind turbine skins

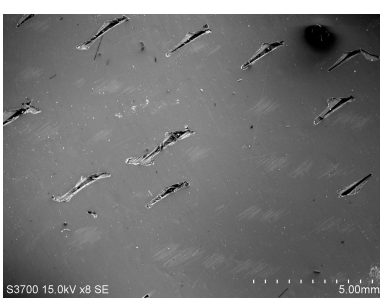

(a) Calibration sample.

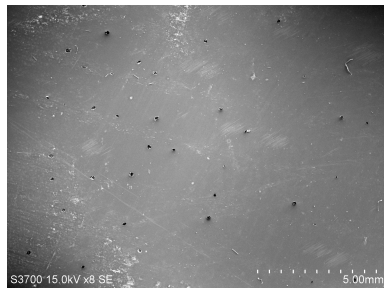

(c) Experimentation sample.

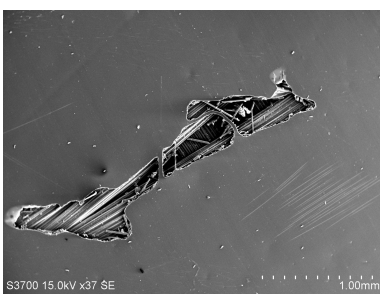

(b) Close-up.

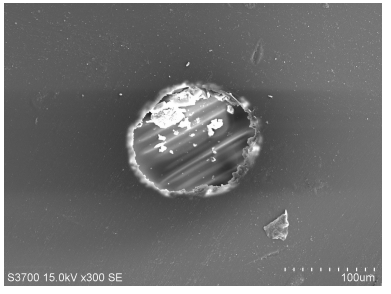

(d) Close-up).
Figure 3: SEM image of control samples.

and also to address the research gap of glass fibre analysis in spherical ice impacts. Composite samples were manufactured using a glass fibre reinforcement and an epoxy-based resin. Triaxial stitched E-glass with a $0 /-45 /+45$ orientation was selected to be equivalent to wind turbine blade skins used in industry. A composite plate of $4 \mathrm{~mm}$ thickness was created using 5 layers of reinforcement together with the epoxy resin and an extra-slow hardener in vacuum infusion. The simple five-layered configuration was used to provide thickness without any additional structure. Using a water jet cutter and sacrificial plate protection, $56.7 \mathrm{~mm}$ sample discs were extracted from the composite plate. Through a "burn-off" procedure, the average fibre volume fraction of three samples was found to approximately 0.6 with a void content of $2.12 \%$.

Two example control samples are displayed in Figure 3 The first sample (Figures 3a and 3b) represents the lower quality sample that has not been properly wetted. The absence of matrix material in strips across the sample is all too apparent, with areas of voids up to $2.5 \mathrm{~mm}$ in length. Samples that exhibited similar levels of wetting were rejected from experimentation for damage evaluation but were included for the calibration procedure, discussed in the next section. The second sample (Figures 3c and 3d shows a much-improved surface quality, with no immediate signs of exposed fibres. However, much smaller circular voids or pits are still present, roughly $100 \mu \mathrm{m}$ in diameter, which are spread quite evenly about the surface, presumably caused by the presence of tiny air bubbles in the system. There also appears to be the slightest hint of fibre direction in 


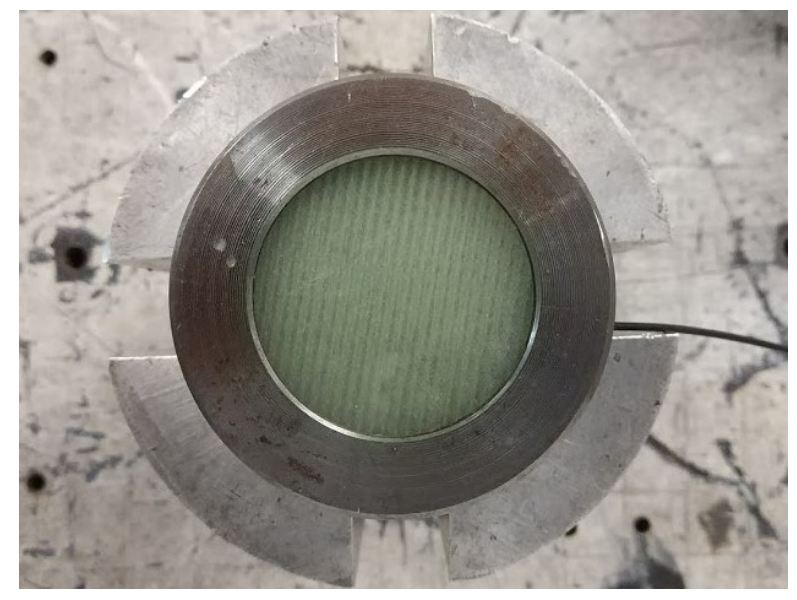

Figure 4: Composite clamping arrangement with force transducer attached.

both control samples close to the surface of the epoxy, that appear take the form of light scratches in the $45 \mathrm{deg}$ direction.

The velocity of the ice projectiles was measured using a light gate attached to the end of the barrel. A dynamic force transducer with a voltage sensitivity of approximately $2.2 \mathrm{mV}$ was used in conjunction with a conditioning amplifier to measure the force of impact. This was attached to the composite clamping arrangement, as shown in Figure 4. Force and velocity information was collected using a National Instruments (USB6210) DAQ device, with a maximum individual sampling rate of $250 \mathrm{kS} / \mathrm{s}$, which was reduced to $83.3 \mathrm{kS} / \mathrm{s}$ when utilising two channels for velocity and one channel for force measurement.

\subsection{Calibration}

An extensive calibration campaign was undertaken to not only ascertain the specified pressure and resultant velocity for each hailstone but to find an experimental procedure that would provide a sufficient level of consistency and validity amongst all the firing scenarios. A primary consideration was the SHI integrity before impact, especially with the heightened sensitivity to environmental temperature of these much smaller manufactured hailstones.

The experimental apparatus was housed in a laboratory with an ambient temperature of $15-20^{\circ} \mathrm{C}$. The manufactured SHI was transported from the storage freezer to an electric cool box in the laboratory, chilled to temperatures of $-5^{\circ} \mathrm{C}$, prior to firing. The individual projectiles were quickly but safely loaded into their respectively sized plastic sabots, then the detachable barrel which was locked into the breach ready to be fired.
After numerous trials, observations and adjustments of the experimental procedure it was decided that only five SHI projectiles should be transported at a time, to mitigate the influence of the environmental procedure.

Once the overall experimental methodology had been finalised the pressure $(p)$-velocity $\left(u_{0}\right)$ calibration could be initiated. The different hailstones were fired at least five times at intervals of 0.5 bar from 0.5 bar -4 bar, with the exception of the $20 \mathrm{~mm}$ diameter projectile which required a minimum of 0.6 bar in order to be released from the sabot. All four average curves appeared to follow a trend, albeit with some variance, close to the form of $u_{0}=a p^{1 / 5}+c$ with the velocity levelling off at around 3 bar. The $10 \mathrm{~mm}$ SHI followed the emulation closest with an $R^{2}$ value of 0.997 . The $20 \mathrm{~mm}$ was the least predictable at $R^{2}=0.947$. Despite the motivation to include the highest velocity possible, in order to represent the uppermost wind turbine tip speeds, it was unlikely that this could be consistently achieved across all the diameters. The target velocities were selected to be $50 \mathrm{~m} \mathrm{~s}^{-1}, 65 \mathrm{~m} \mathrm{~s}^{-1}, 80 \mathrm{~m} \mathrm{~s}^{-1}$ and $95 \mathrm{~m} \mathrm{~s}^{-1}$, relating to the tip speed of typical wind turbines and the span-wise location of impact on the blade.

The impact force history for these tests was also analysed to determine whether a specified velocity would result in a consistent force profile. For all cases, the measured force resembled a damped sinusoidal pattern occurring at similar wavelengths for the different diameters, with the maximum force occurring at the first peak. The resting noise of the dynamic force transducer was found to be less than $1 \mathrm{~N}$ Overall, the measured force for each case was effectively damped out around the $5 \mathrm{~ms}$ mark. The average peak forces for all the impacts were compared to the peak force calculated using the Roisman \& Tropea [16] equation for spherical impact on a rigid wall, shown in Equation 1.

$$
F \approx \frac{4 \pi}{3} r_{0}^{2} u_{0} \rho^{\frac{1}{2}} \Upsilon^{\frac{1}{2}}
$$

Here $\rho$ was taken from the mean measured mass of the ice spheres and the compressive failure stress $(\Upsilon)$ was determined using a quasi-static yield strength $\left(\Upsilon_{\text {stat }}\right)$ of 5.2 MPa, taken from Tippmann et al. [10]. This quasistatic yield strength is applicable to strain-rates less than $0.1 \mathrm{~s}^{-1}$, with greater stain rates accounted for by the relation, obtained from fitted data by Roisman \& Tropea [16], which is displayed in Equation 1 .

$$
\Upsilon=\Upsilon_{s t a t} \exp \frac{u_{0}}{9 u_{c}}
$$

As the relation concerns impacts onto a solid, rigid surface, the values estimated from it were expected to 
be higher than that for composite impacts. The peak forces of the $10 \mathrm{~mm}, 15 \mathrm{~mm}$ and $20 \mathrm{~mm}$ diameter SHI compared well to those calculated using Equation 1 but the average peak forces for all the separate $5 \mathrm{~mm}$ diameter experimental impacts fell well short of the predicted values. The mean experimental force histories for the highest firing pressures can be viewed in Figure 5, along with the closest individual example, determined by root mean square error (RMSE). The harmonics of the sinusoidal pattern were found to be the greatest at the highest velocities.

This is also apparent when analysing the relationship between the calculated kinetic energy of the SHI and the measured peak force upon impact. Figure 6 displays both the experimental data as well as similar trendlines for higher diameter SHI described by Tippmann et al. [10]. Again, where the other experimental diameters of SHI compare favourably with the Tippmann data, the peak force for the $5 \mathrm{~mm}$ trendline is considerably diminished for increasing kinetic energy. Limitations of the DAQ in force measurement were encountered when the $\pm 10 \mathrm{~V}$ was exceeded for certain instances of firing the $20 \mathrm{~mm}$ projectile at maximum pressure. At these higher velocities, the force profile and thus maximum force may not be accurately represented.

Lastly, a high-speed video camera was employed in order to ascertain the condition of the ice sphere prior to impact and the authentic contact with the centre of the composite surface upon impact. The recordings allowed confirmation of the integrity of the different diameter SHI and the correct collision with the composite disc, with the detection of shards and/ or smaller particles, if present. The limit of resolution of the camera with optimum lighting was $128 \times 120$ at a frame rate of 5000 frames per second.

\subsection{Experimental Procedure}

As the initial quality of the composite samples was critical, they were carefully checked and 32 were selected for further examination. Originally the full matrix of variables was to involve the four SHI diameters [ $5 \mathrm{~mm}, 10 \mathrm{~mm}, 15 \mathrm{~mm}, 20 \mathrm{~mm}$ ] at the four different target velocities [ $50 \mathrm{~m} \mathrm{~s}^{-1}, 65 \mathrm{~m} \mathrm{~s}^{-1}, 80 \mathrm{~m} \mathrm{~s}^{-1}, 95 \mathrm{~m} \mathrm{~s}^{-1}$ ] for five different sets of "number of impacts" [1, 5, 10, 25, 50]. The maximum number of impacts (50) was taken from the largest number of impacts in one year, from the most prominent location in the meteorological study by Macdonald et al. [13]. Although the number of composite samples limited the total number of experiments possible, the full range of realistic hailstone diameters, velocities and number of impacts was covered albeit at the expense of a few missing data points. There were slight variations in the target and recorded velocity for all the experiments, which are documented in Appendix and from which the full set of experimental tests achieved on the samples can be inferred. Overall, the error bars for all the multiple impact velocities were smallest for the $10 \mathrm{~mm}$ diameter SHI, with the $15 \mathrm{~mm}$ and $20 \mathrm{~mm} \mathrm{~mm}$ cases equally variable. Both the $5 \mathrm{~mm}$ and $20 \mathrm{~mm}$ diameter SHI struggled to reliably reach the higher-end target velocity of $95 \mathrm{~m} \mathrm{~s}^{-1}$.

The assessment of damage was carried out using three different methods of analysis: mass loss, optical (or reflected light) microscopy and scanning electron microscopy (SEM). Prior to it being subject to its programme of experimentation, a sample was weighed using a measuring balance with a resolution of $0.00001 \mathrm{~g}$. Upon completion of the testing regime it was left to dry for at least 24 hours at a slightly elevated temperature of $30^{\circ} \mathrm{C}$ and then compared to the weight before experimentation. The samples were also compared before and after impacts of SHI using a 20x magnification optical microscope to ascertain whether there was any obvious damage apparent before utilisation of the electron microscope. As the composite samples are non-metallic, the surfaces of the disc had to be coated in conductive gold to enable detailed imaging using the electron microscope. For that reason direct comparison of the samples using SEM before and after experimentation was not possible.

\section{Results}

\subsection{Impact force}

The differences in the peak force were quite distinct for each size of hail, with ranges of approximately $15 \mathrm{~N}-65 \mathrm{~N}, 400 \mathrm{~N}-1500 \mathrm{~N}, 1350 \mathrm{~N}-3960 \mathrm{~N}$ and $2300 \mathrm{~N}-$ $4820 \mathrm{~N}$ for the respective $5 \mathrm{~mm}, 10 \mathrm{~mm}, 15 \mathrm{~mm}$ and $20 \mathrm{~mm}$ diameters of SHI. The mean velocity vs. peak force relationships of the separate diameters were not as pronounced. The total peak forces subjected on a sample were aggregated and are displayed in Figure 7 . The total peak force subjected to a sample was useful in highlighting particular examples that would make for interesting comparisons. For instance, $10 \mathrm{~mm}$ diameter SHI at 50 impacts vs. $20 \mathrm{~mm}$ at 10 impacts; and the specific case of 50 impacts of $15 \mathrm{~mm}$ diameter SHI at a mean velocity of $\sim 80 \mathrm{~m} \mathrm{~s}^{-1}$ vs. 50 impacts of $20 \mathrm{~mm}$ at $\sim 50 \mathrm{~m} \mathrm{~s}^{-1}$.

The aggregation of the peak forces were also compared with the predicted values calculated using the Roisman \& Tropea relation. Overall the total forces were fairly similar, albeit with some notable exceptions. The 


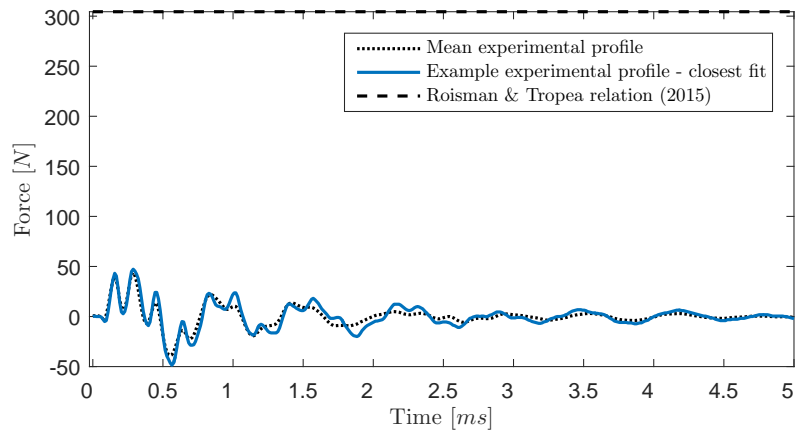

(a) $5 \mathrm{~mm}$

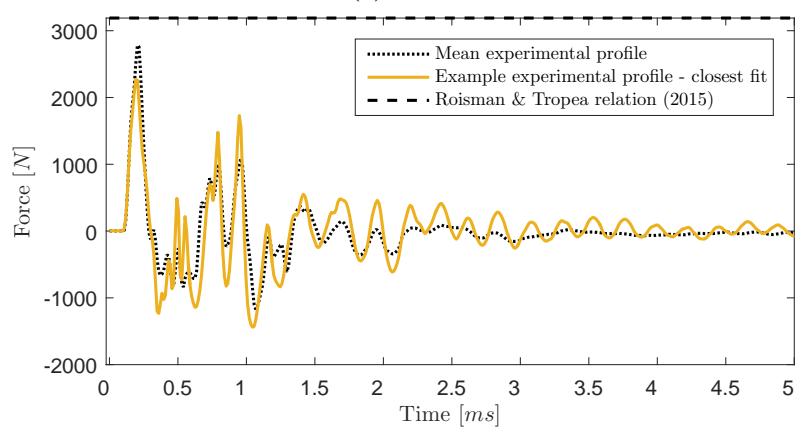

(c) $15 \mathrm{~mm}$.

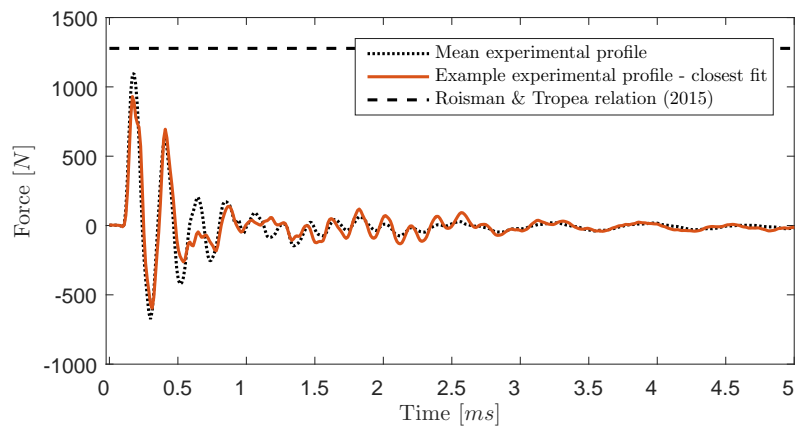

(b) $10 \mathrm{~mm}$.

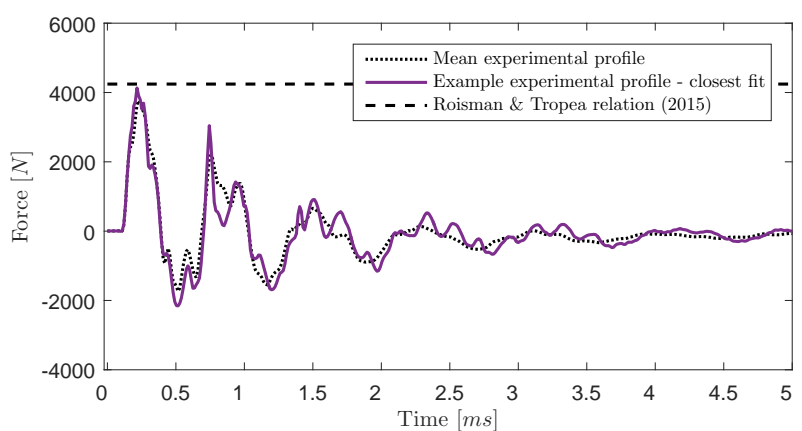

(d) $20 \mathrm{~mm}$.

Figure 5: Mean force transducer impact profiles compared to most similar individual example.

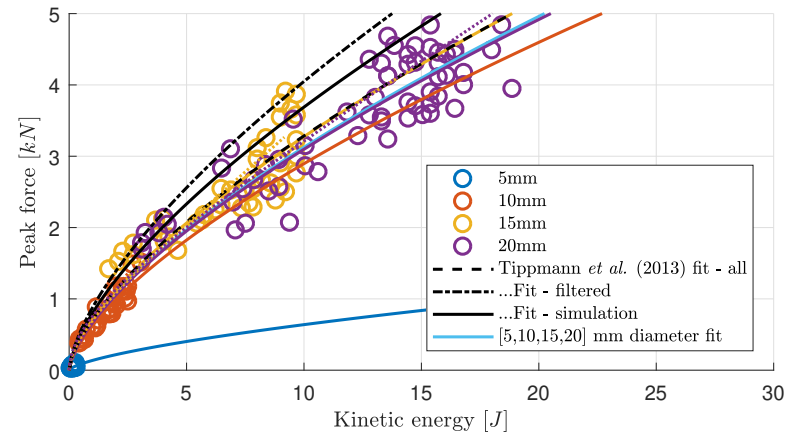

Figure 6: Peak force versus kinetic energy relationship (individual diameters) compared with data from Tippmann et al. [10] (Solid coloured lines represent the fitted data of the separate diameters indicated by the markers in the legend). totals of the predicted $5 \mathrm{~mm}$ impacts are small in magnitude, with a maximum cumulative force of $<15 \mathrm{kN}$. This maximum value was greatly diminished in the experimental tests and did not exceed $3 \mathrm{kN}$. The fifty and twenty five impacts of $20 \mathrm{~mm} \mathrm{SHI} \mathrm{at} \sim 50 \mathrm{~m} \mathrm{~s}^{-1}, 15 \mathrm{~mm}$ SHI at $\sim 80 \mathrm{~m} \mathrm{~s}^{-1}$ were the most obvious cases where the total experimental force exceeded the prediction.

\subsection{Mass change}

The mass change resulting from SHI impacts was very low across the full range of samples and in fact there were instances where this was interpreted as a small amount of mass gain. The maximum mass loss/gain from the experimental study did not exceed $4 \mathrm{mg}$, which is roughly equivalent to a $0.02 \%$ mass change of the mean sample mass (measured prior to impact). The average mass change across the samples was approximately $0.0043 \%$ of the mean sample mass.

\subsection{Optical Microscopy}

There was no detectable change in the condition of samples following hail impact, with the exception of the sample subject to 50 impacts of $15 \mathrm{~mm}$ at a mean velocity of $85.6 \mathrm{~m} \mathrm{~s}^{-1}$. This showed score marks at 


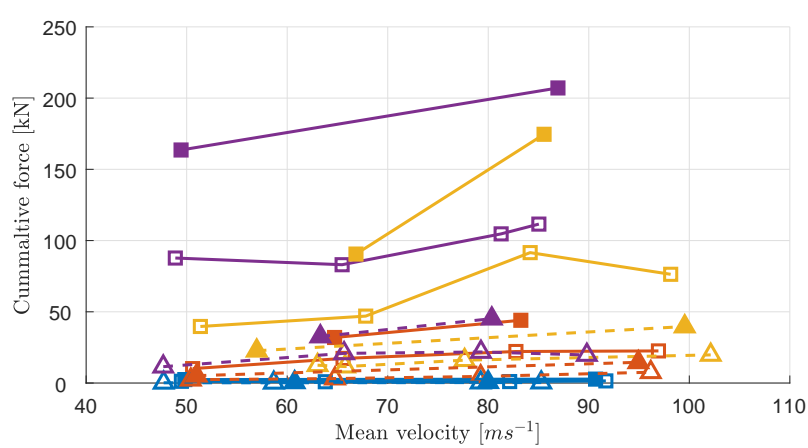

(a) All

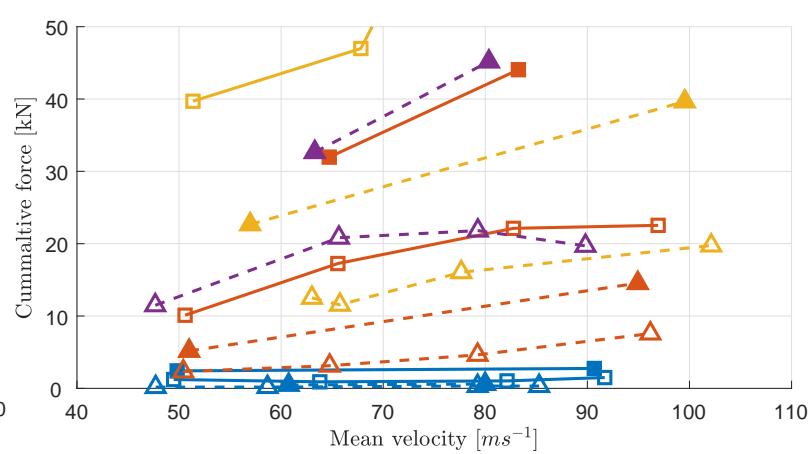

(b) $<50 \mathrm{kN}$

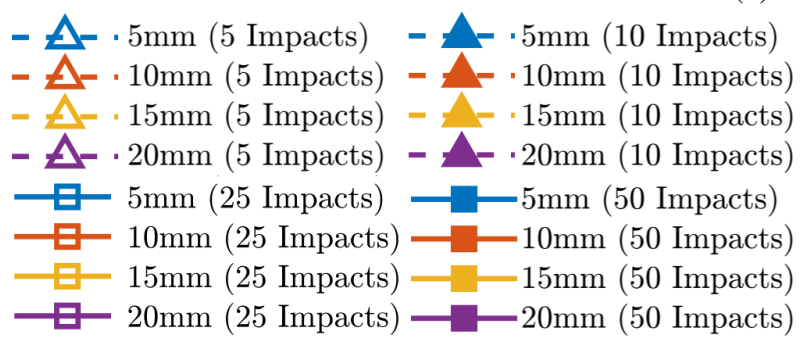

(c) Legend for Figure 7

Figure 7: Total measured force subjected to each sample.

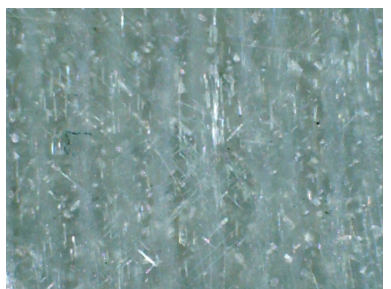

(a) Before

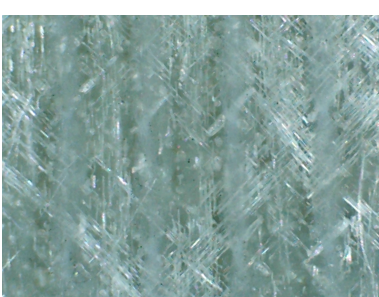

(b) After
Figure 8: Optical surface quality of sample subject to 50 impacts of $15 \mathrm{~mm} \mathrm{SHI}$ at a mean velocity of $85.6 \mathrm{~m} \mathrm{~s}^{-1}$

oblique angles that follow the $-45 \mathrm{deg}$ and $45 \mathrm{deg}$ (Figure 8). However, it should be noted that the surface quality of this composite prior to experimentation appeared slightly worse than other samples that were to be subject to 50 impacts. On the bottom surface of the composite samples, an internal whitening was observed for the single impact of both $15 \mathrm{~mm}$ and $20 \mathrm{~mm}$ diameter SHI at high velocities, displayed in Figure 9, which was not observed in the low velocity counterparts. The damage exhibited was exacerbated in the multiple impact variants.

No other noteworthy damage indicators were found in any other samples and consequently no damage trend, with regards to size or velocity of SHI could be deter-

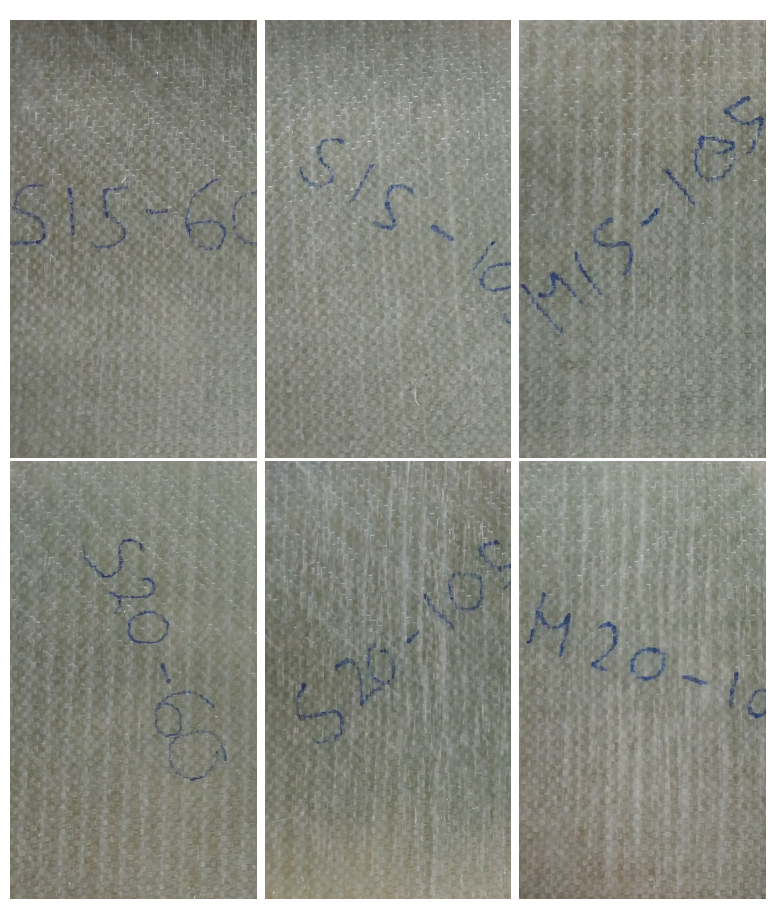

Figure 9: Bottom surfaces of experimental discs for $15 \mathrm{~mm}$ and $20 \mathrm{~mm}$ SHI impacts (1st Row L-R) S15-V1, S15-V4, M15-V4; (2nd Row LR) S20-V1, S20-V4, M20-V4 (Please note that the velocity description on each sample label in the images are $10 \mathrm{~m} \mathrm{~s}^{-1}$ less than the subjected velocity, for all samples). 
mined at this level of microscopy.

\subsection{SEM Microscopy}

Scanning electric microscopy was carried out for all samples. There were definite examples of surface damage for selected specimens across the full sample survey. Figure 10 displays four separate SEM images, along with their associated scale, that describe notable types of damage that were prevalent in such samples. One of the most obvious markers of damage observed under SEM is "fibre breakage", as shown in Figure 10a In this example the fibres appeared to be pulled through to breach the surface and some emerge loose near the damaged site, along with a minor collection of debris. Smaller Figure $10 \mathrm{~b}$ represents the contrasting case of the same diameter SHI, impacting a composite disc the same number of times but at the lowest tested mean velocity $\left(49.5 \mathrm{~m} \mathrm{~s}^{-1}\right)$. A large and irregular area of epoxy removal is displayed, which was only found for this particular example. A close-up of the feature's centre shows that, in contrast to the previous image, the fibres underneath the matrix remain largely undisturbed. Two other forms of damage, shown in Figures 10c and 10d are taken from SEM of the same sample (10 impacts of $15 \mathrm{~mm} \mathrm{SHI}$ at a mean velocity of $99.5 \mathrm{~m} \mathrm{~s}^{-1}$ ). This represents the fastest average velocity recorded across the multiple impact survey, with certain instances exceeding $100 \mathrm{~m} \mathrm{~s}^{-1}$. Figure $10 \mathrm{c}$ showcases a large scar or furrow, roughly $2 \mathrm{~mm}$ in length. This is the largest defect of its kind found across the samples and a clear indicator of the cutting/ploughing category of tribological wear. The final form of damage is displayed in Figure 10d, where an abundance of debris, of what appears to be a mixture of small shards of matrix and loose fibres spread across the scene.

Table 1 summarises the damage observed by the different diameters of SHI, for the upper and lower bounds of both experimental velocity and number of impacts. In this form of qualitative analysis, the surface damage is stated as being either "minimal", where little or no damage was found, or "notable" when obvious forms, similar to those in Figure 10, were described. Only the largescale matrix removal from the 50 impacts of $20 \mathrm{~mm}$ displayed any noteworthy microscopic damage for the low velocity cases. Conversely, notable damage was identified for both low and high number of impacts of the $15 \mathrm{~mm}$ and $20 \mathrm{~mm}$ SHI at high velocity. The table also highlights that the average velocity for the $15 \mathrm{~mm} \mathrm{SHI}$ is greater $\left(\sim 10 \mathrm{~m} \mathrm{~s}^{-1}\right)$ than what was achieved for the $20 \mathrm{~mm}$, at these high pressures. Descriptions of minor damage were observed for the smaller $5 \mathrm{~mm}$ and $10 \mathrm{~mm}$ diameter SHI at these greater velocities but not to the same degree, even after a larger number of impacts.

There are also interesting specific damage comparisons, as discussed previously with regards to Figure 6 . The damage inflicted by the separate cases of $50 \mathrm{im}$ pacts of $10 \mathrm{~mm}$ and 10 impacts of $20 \mathrm{~mm}$ were both relatively minor, leaving little for comparison. However, there are clear differences between the surface conditions of the sample subject to 50 impacts of $20 \mathrm{~mm}$ SHI at a mean velocity of $49.4 \mathrm{~m} \mathrm{~s}^{-1}$, compared with that inflicted by 10 impacts of $15 \mathrm{~mm} \mathrm{SHI}$ at a mean velocity of $49.4 \mathrm{~m} \mathrm{~s}^{-1}$, which were described earlier in Figure 10 . Certainly, the area of matrix absence on the sample associated with the lower velocity $20 \mathrm{~mm}$ impacts is large but the violence of the scene caused by the higher velocity, yet smaller $15 \mathrm{~mm}$ is pronounced, even for a much lower number of impacts.

Although SEM images of each sample prior to experimentation were not available, a control specimen was inspected to examine the surface quality of an unimpacted composite. This revealed the presence of evenly spread, often circular, voids or pits, roughly $100 \mu \mathrm{m}$ in diameter. The slightest hint of fibre direction close to the surface also appeared in the form of light scratches at an oblique angle. Both characteristics are seen in some of the images in Figure 10 and were assumed to be part of the manufacturing process and not an indicator of damage.

\section{Discussion}

The study of smaller, more prevalent sizes of SHI is a novel aspect of this investigation compared with the extreme diameters found in the literature. These more modest diameters of hail also make for a more challenging testing environment and there have been a number of limitations of the campaign. Despite a lengthy calibration process, concerns must be raised regarding the integrity of the $5 \mathrm{~mm}$ category of hail. Unlike SHI of larger diameters, the peak impact force from $5 \mathrm{~mm}$ diameter SHI was significantly undervalued; and beyond a certain firing pressure, the force pattern appeared to behave differently. The pressure required to cause a phase change from solid to liquid in ice, taken from adiabatic shock Hugoniot curves [6], is thought to be extremely large ( $\geq 23.5 \mathrm{GPa}$ ). The maximum pressures from all diameters of SHI, taken from peak force measurements and the estimated contact area at that time, are found to be less than $0.09 \mathrm{GPa}$. The generation of any liquid solution on the surface of the composite sample must instead be driven by temperature. It is certainly likely that although the inner structure of the SHI may be solid ice, 


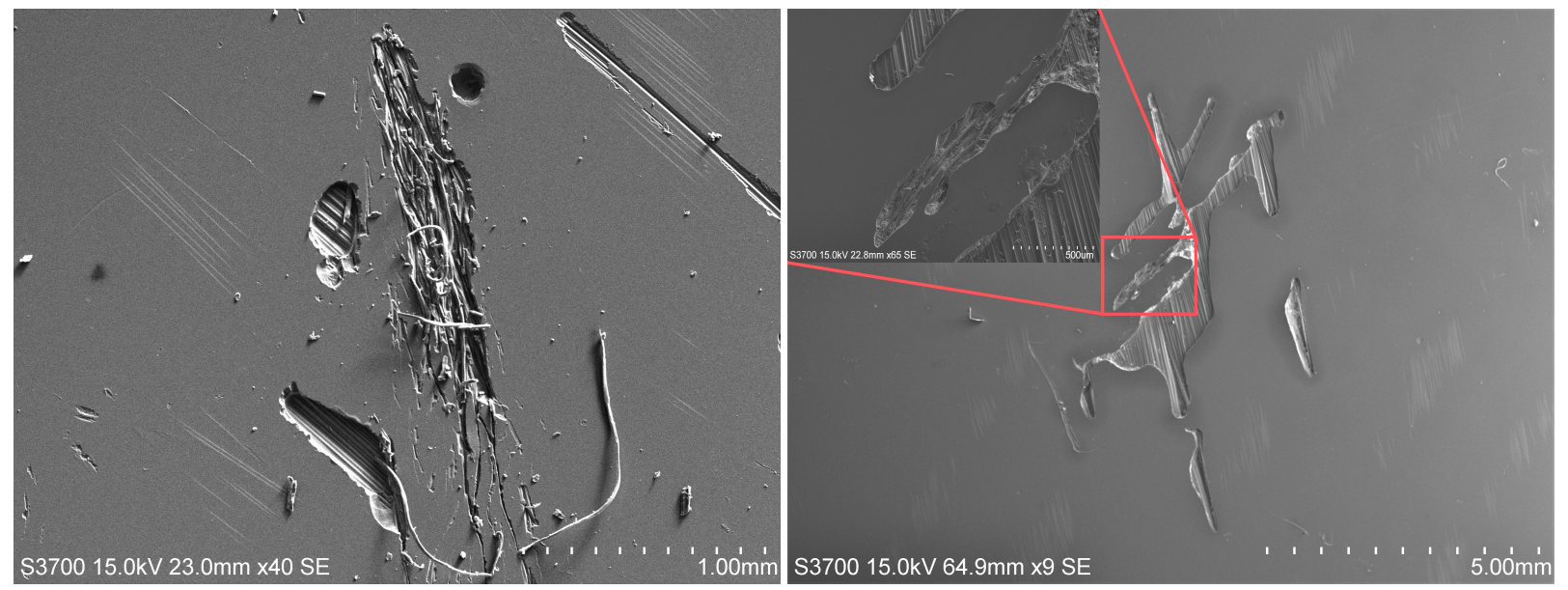

(a) Fibre breakage - 50 impacts of $20 \mathrm{~mm} \mathrm{SHI}$ at a mean velocity (b) Matrix removal - 50 impacts of $20 \mathrm{~mm}$ SHI at a mean velocof $86.9 \mathrm{~m} \mathrm{~s}^{-1}$.

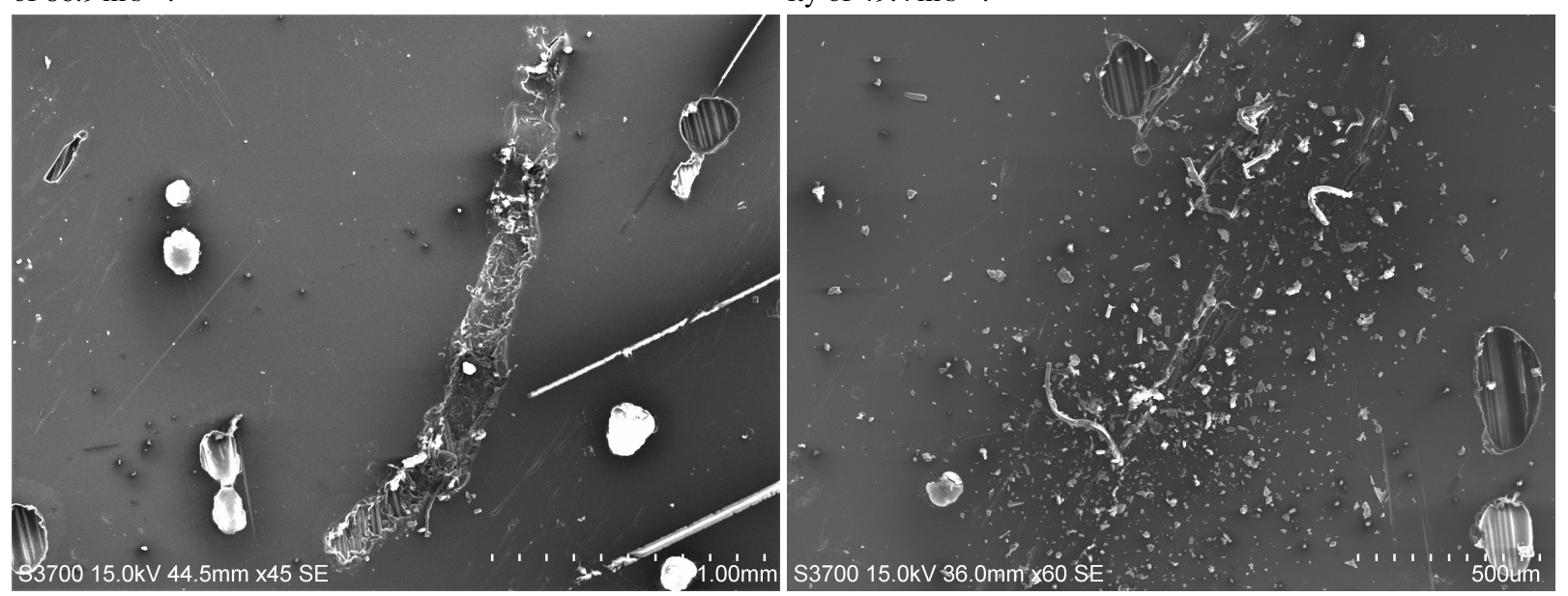

(c) Scarring - 10 impacts of $15 \mathrm{~mm} \mathrm{SHI}$ at a mean velocity of (d) Scattered debris - 10 impacts of $15 \mathrm{~mm}$ SHI at a mean veloc$99.5 \mathrm{~m} \mathrm{~s}^{-1}$.

ity of $99.5 \mathrm{~m} \mathrm{~s}^{-1}$.

Figure 10: Notable forms of damage from SEM images. 
Table 1: Damage observed under SEM of different diameters of SHI, fired at low and high velocities, for different numbers of impacts.

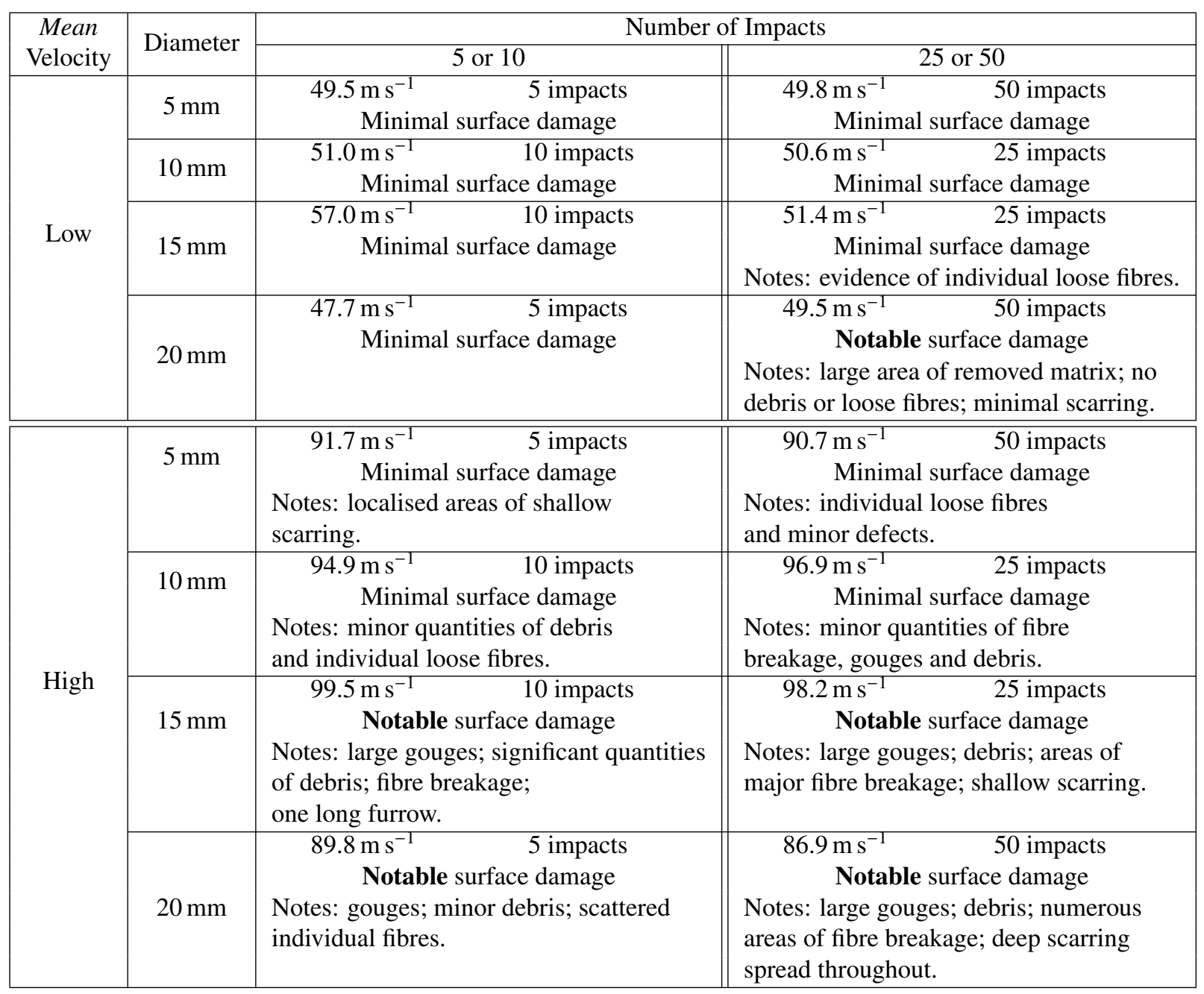


the outer surface may have started to melt, this would result in a different consistency of projectile and thus mechanism of impact. Although it is recommended that future evaluation of these sizes of hail be conducted in a fully controlled laboratory cold room to further examine this behaviour, it is possible that the temperature differentials may exist in a wind farm setting and the consistency of projectile may reflect what happens in a realistic scenario.

Mass loss did not appear to be a valid indicator of damage for these investigations, as the mass change reported across all the composite samples was exceptionally low. This may indicate that erosive category of damage experienced by wind turbine blades is not directly caused by hail. However, the use of protective coatings was not included in the scope of this study and so further analysis should be undertaken to fully discount the role of hailstones in blade leading edge erosion. The condition of the composite surface, examined optically after experimentation, was not markedly changed except in the individual case of fifty impacts of $\sim 80 \mathrm{~m} \mathrm{~s}^{-1} 15 \mathrm{~mm}$ SHI. There were several indications of damage using the scanning electron microscope that were undetected by the other methods. Unsurprisingly, the more severe damage was experienced using the larger $15 \mathrm{~mm}$ and $20 \mathrm{~mm}$ diameter SHI for impacts at higher velocity and a higher number of impacts. The effects of $10 \mathrm{~mm}$ impacts was detectable under SEM but noticeably less. The damage sustained from the $5 \mathrm{~mm}$ SHI was minor, even after a cumulation of a large number of impacts. The resultant effects caused by extreme velocity impacts ( $\geq 95 \mathrm{~m} \mathrm{~s}^{-1}$ of $15 \mathrm{~mm}$ ) SHI were still apparent even as low as ten impacts. Together with the less severe effects of 50 impacts of lower velocity $20 \mathrm{~mm}$, there is the suggestion of a a threshold velocity for each diameter of SHI, beneath which surface defects are minimal.

As the damage evaluation in this investigation was focused around erosion and the condition of the composite surface, there could be sub-surface damage or a change in material properties due to SHI impacts that have been undetected in the analysis.

\section{Conclusions}

An experimental campaign was undertaken to evaluate the cumulative effect of $5 \mathrm{~mm}, 10 \mathrm{~mm}, 15 \mathrm{~mm}$ and $20 \mathrm{~mm}$ diameter simulated hail ice (SHI) impacting on glass-fibre reinforced polymers, at speeds associated with turbine operation. Mass loss measurements did not provide viable indications of erosive damage. Only using scanning electron microscopy were the effects of

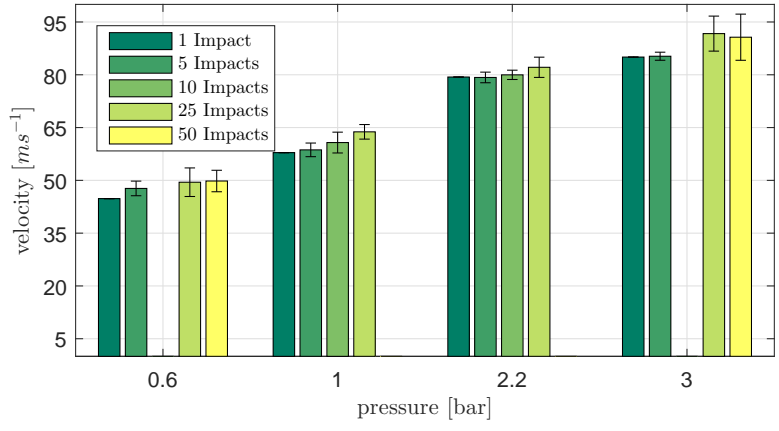

Figure 11: Average velocities against firing pressure for different number of impacts of $5 \mathrm{~mm}$ diameter SHI impacts.

surface interaction made visible. The most pronounced of which was "fibre-breakage", present in specimens subject to large diameter SHI $(15 \mathrm{~mm}$ and $20 \mathrm{~mm})$, at a high mean velocity. Here reinforcement fibres were shown to be ripping through the epoxy resin and exposing the material beneath. Scattered debris and localised scarring were also discovered in certain specimens, particularly for $15 \mathrm{~mm}$ diameter SHI at a high mean velocity $\left(>95 \mathrm{~m} \mathrm{~s}^{-1}\right)$. Large-scale matrix removal was only observed the individual case of $20 \mathrm{~mm}$ diameter SHI, for the largest number of impacts at the lowest mean velocity. Again, this did not translate to measurable material mass loss.

Despite meteorological data highlighting the far more prevalent smaller diameter hail, this experimental survey did not find any noteworthy surface damage from multiple impacts of $5 \mathrm{~mm}$ and $10 \mathrm{~mm}$ diameter SHI. Even for a large number of impacts, the severity of damage associated with smaller sizes of hail was minimal compared with that of the larger sizes, at a reduced number of impacts. Impact velocity was shown to be a key factor in the severity of surface damage, with even the larger sizes of hail displaying few noteworthy characteristics at the lowest mean velocity $\left(\sim 50 \mathrm{~m} \mathrm{~s}^{-1}\right)$ at a high number of impacts, suggesting the presence of a damage threshold velocity.

\section{Acknowledgements}

The authors also gratefully appreciate and acknowledge the support of the UKs Engineering and Physical Sciences Research Council via the University of Strathclydes Wind Energy Systems Centre for Doctoral Training, grant number EP/G037728/1. 


\section{Appendices}

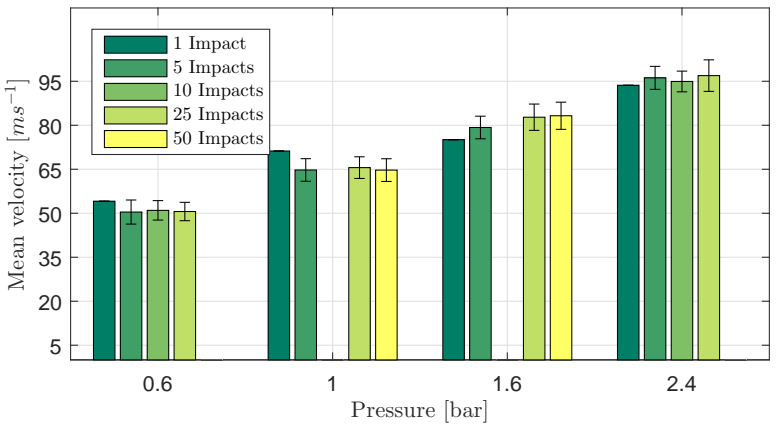

Figure 12: Average velocities against firing pressure for different number of impacts of $10 \mathrm{~mm}$ diameter SHI impacts.

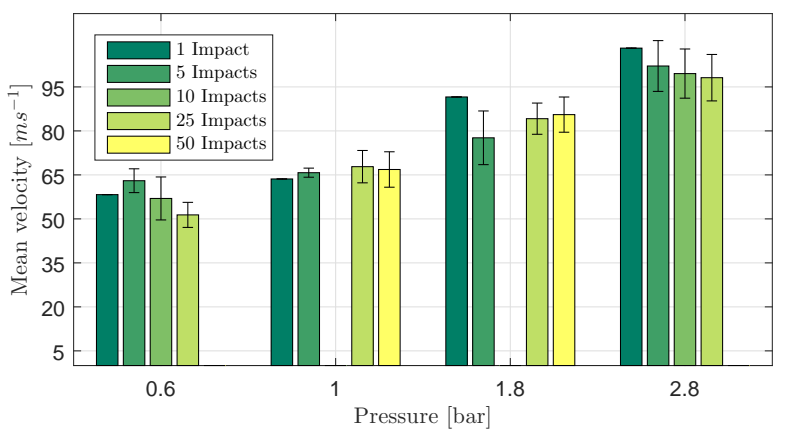

Figure 13: Average velocities against firing pressure for different number of impacts of $15 \mathrm{~mm}$ diameter SHI impacts.

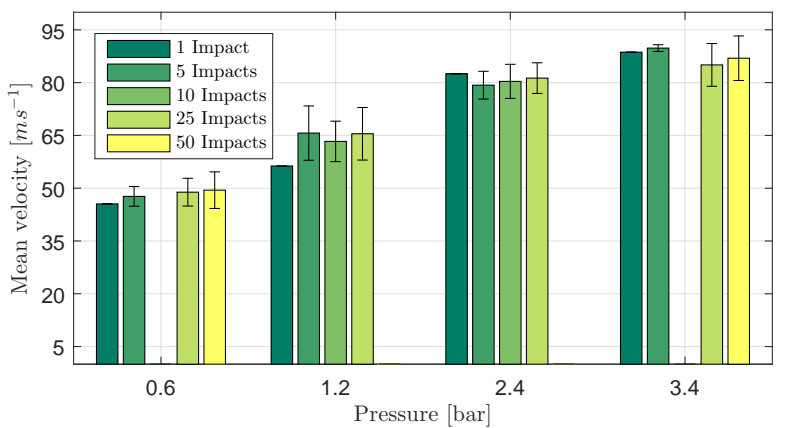

Figure 14: Average velocities against firing pressure for different number of impacts of $20 \mathrm{~mm}$ diameter SHI impacts.

\section{References}

\section{References}

[1] Bladena, Vattenfall, EON, Statkraft, ENGIE, and K. x. THOMSEN, "Blade Inspections - INSTRUCTION," tech. rep., 2016.

[2] M. Mahinfalah and R. A. Skordahl, "The effects of hail damage on the fatigue strength of a graphite/epoxy composite laminate," Compos. Struct., vol. 42, pp. 101-106, jun 1998.

[3] World Meteorological Organisation, "Manual on Codes: Part A - Alphanumeric Codes," Tech. Rep. 2, World Meteorological Organisation, Geneva, 2011.

[4] E. M. Schulson, "Brittle failure of ice," Eng. Fract. Mech., vol. 68, pp. 1839-1887, dec 2001.

[5] J. J. Petrovic, "Review Mechanical properties of ice and snow," J. Mater. Sci., vol. 38, pp. 1-6, 2003.

[6] R. Olsson, R. Juntikka, and L. E. Asp, "High Velocity Hail Impact on Composite Laminates - Modelling and Testing," in Dyn. Fail. Compos. Sandw. Struct. (S. Abrate, B. Castanié, and Y. D. S. Rajapakse, eds.), vol. 192 of Solid Mechanics and Its Applications, pp. 393-426, Springer Netherlands, 2013.

[7] H. Kim and K. T. Kedward, "Modeling Hail Ice Impacts and Predicting Impact Damage Initiation in Composite Structures," AIAA J., vol. 38, no. 7, pp. 1278-1288, 2000.

[8] H. Kim, D. A. Welch, and K. T. Kedward, "Experimental investigation of high velocity ice impacts on woven carbon/epoxy composite panels," Compos. Part A Appl. Sci. Manuf., vol. 34, no. 1, pp. $25-41,2003$.

[9] H. Kim and J. N. Keune, "Compressive strength of ice at impact strain rates," J. Mater. Sci., vol. 42, no. 8, pp. 2802-2806, 2007.

[10] J. D. Tippmann, H. Kim, and J. D. Rhymer, "Experimentally validated strain rate dependent material model for spherical ice impact simulation," Int. J. Impact Eng., vol. 57, no. 0, pp. 43-54, 2013.

[11] P. R. Field, W. Hand, D. Cappelluti, G. McMillan, A. Foreman, A. Stubbs, and M. Willows, "Hail Threat Standardisation - Final report," research project easa.2008/5, EASA, 2008.

[12] G. J. Appleby-Thomas, P. J. Hazell, and G. Dahini, "On the response of two commercially-important CFRP structures to multiple ice impacts," Compos. Struct., vol. 93, no. 10, pp. 26192627, 2011.

[13] H. Macdonald, D. Infield, D. H. Nash, and M. M. Stack, "Mapping hail meteorological observations for prediction of erosion in wind turbines," Wind Energy, pp. n/a-n/a, apr 2015.

[14] R. Juntikka and R. Olsson, "Experimental and modelling study of hail impact on composite plates," in ICCM Int. Conf. Compos. Mater, 2009.

[15] H. Park and H. Kim, "Damage resistance of single lap adhesive composite joints by transverse ice impact," Int. J. Impact Eng., vol. 37, no. 2, pp. 177-184, 2010.

[16] I. V. Roisman and C. Tropea, "Impact of a crushing ice particle onto a dry solid wall," Proc. R. Soc. A Math. Phys. Eng. Sci., vol. 471, p. 20150525, nov 2015. 